\title{
Hypoplastic Right Heart Syndrome
}

National Cancer Institute

\section{Source}

National Cancer Institute. Hypoplastic Right Heart Syndrome. NCI Thesaurus. Code C99053.

A rare congenital cardiovascular disorder characterized by severe underdevelopment of the right side of the heart. The infants develop cyanosis shortly after birth. It is a condition that requires immediate emergency treatment. 